\title{
The Role of Deception in Complex Social Interaction
}

\author{
Susan A. J. Stuart \\ Published in Cogito, Vol. 12, No. 1, 1998
}

Social participation requires certain abilities: communication with other members of society; social understanding which enables planning ahead and dealing with novel circumstances; and a theory of mind which makes it possible to anticipate the mental state of another. In childhood play we learn how to pretend, how to put ourselves in the minds of others, how to imagine what others are thinking and how to attribute false beliefs to them. Without this ability we would be unable to deceive and detect deception in the actions of others, and our ability to interact within our social group would be greatly impaired. In this paper I claim that the capacity for deception is necessary for a theory of mind, and a theory of mind is necessary for complex social interaction.

\section{Introduction}

I start by examining the criteria that are necessary for intelligent social interaction, and then go on to explain what is meant by a 'theory of mind' (Premack and Woodruff (1978)) and why such a concept is important in a consideration of social groups. I then move on to examine the role of deception in humans, and in non-human animals that form social groups. Finally I look at the problem of mindblindness in people with autism and what implications their condition has for their ability to interact in a complex social environment.

\section{Communication}

Fundamental to most complex social groups is the ability to communicate successfully. Dawkins argues that Communication forms the fabric of animal social life. It is the way animals influence one another to come together in schools, flocks, and herds as well as to space out and to defend territories. It includes the way that the sexes interact in courtship, rivals settle disputes without fighting and parents care for their young. In fact, looking at the way in which animals spend their time, it is striking how much of it they spend either influencing, or being influenced by, the behaviour of other animals - in other words, in some form of communication. (Dawkins 1995, p.71). 
What exactly is meant by communication? A working definition of it might be the intended conveyance of information (Shannon and Weaver (1949)). This rules out information that is conveyed by accident, for example, an injured animal might be detected by a predator because of an unwitting movement or noise; and it would rule out the sorts of action that might be considered instinctual, for example, honey bee dances. Moving up the phylogenetic scale towards mammals, and in particular primates, communication seems to become more intricate, its end being to convey meaning and enable the communicators to share their experiences.

Broadly speaking there are two kinds of communication, linguistic and non-linguistic. Linguistic communication consists of formal symbol systems, like the various human languages. However, with some imagination we might also describe the sound systems that form rudimentary languages, like those associated with dolphins and other primates as linguistic communication. Nonlinguistic communication includes body language, gestures, and externally created signs, for example, indicator lights which communicate a driver's intentions.

Certainly the most complicated and efficient forms of communication are the symbol systems that human beings employ. Nowhere else in the animal kingdom is the conveyance of information and ideas so efficient. We might argue that a society's complexity is mirrored in the general complexity of its system of communication; and we might say that there is a direct correlation between the level of sophistication possessed by a society, its ability to communicate effectively, and the method of communication it employs. Certainly human language communicates a vast array of ideas: abstract thoughts on justice, moral codes, religious tenets, physical object descriptions, and arguably the most complex of all, yet possibly the most fundamental, gossip (Dunbar 1996).

On top of this we manage to communicate a lot of other information by the use of body language and gestures. A careful shrug here or wink there can inform us fairly accurately of anothers 
thoughts or intentions. Cultural rules may govern body language, and understanding these conventions can be as complicated as understanding a foreign language.

Many non-human animals also form social groups: dolphins, chimpanzees, vampire bats, and deer, to name but a few, and their means of communication is, for the most part obviously nonlinguistic, though there may be sounds that they use in a social setting that convey particular sorts of meanings. One example of this can be seen in Cheney and Seyfarths (1990) work on vervet monkeys. Thinking that the sounds made by the monkeys were more than just random noises, they recorded them and played them back through hidden loudspeakers. The monkeys responded in different, but consistent ways to each grunt. Grunts which may sound very similar to the human ear, but which express a range of meanings to the vervet monkeys.

Some of the most obvious signs of non-human communication come from the grooming and chattering that goes on within monkey and ape communities. One monkey grooming another can be a way of intimating a willingness to be an ally, a way of strengthening a friendship, or simply a pleasurable experience with the advantage of keeping the fur clean.

The chattering exhibited by, for example, marmosets and tamarins, serves to keep the members of the group in touch with each other while they are occupied with another task, such as foraging for food. Contact calls can become quite complex as, for example, with the gelada who have calls which are specific enough to enable them to keep in touch with their favourite grooming partners while they are apart.

Lewin has pointed out that both human and non-human primates have an intense social interaction that has little apparent direct bearing on the practicalities of life: in the human sphere we would call it socializing, the making and breaking of friendship and alliances (Lewin 1992, p.46). Such "making and breaking of friendship and alliances" can be seen clearly in this grooming and chattering behaviour. 
It is now thought that humans may have evolved a formal language system as a grooming strategy. After all it is impossible to spend all the time that it would require to physically groom all of the people within your social group (about 150) so language may have evolved as a kind of vocal grooming to allow us to bond larger groups than was possible using the conventional primate mechanism of physical grooming (Dunbar 1996, p.78). A plausible suggestion since it enables us to deal efficiently with more than one person at once, and maintain social bonds over physical distances that would otherwise be insurmountable.

Non-human social groups may not be as complex as human societies, but that the individuals need to convey information relevant to the group within time limits crucial for their continued survival reveals some small measure of their sophistication and success.

\section{Social Understanding}

I shall now examine what is essential for appropriate communication in an ever changing social world, concentrating mainly on monkeys, apes and humans. My rationale for this is, (i) that primates live in a very much more sophisticated kind of social world than other animals do (Dunbar 1996, p.9), and are therefore more likely to use complex forms of communication, and (ii) that although animals further down the phylogenetic scale may operate successfully in their own society, it is unlikely, or at the very least unclear, that they have, or could have, a full-blown theory of mind. I shall return to this point presently.

The chief task for the young of all social species is understanding their social world. Social understanding is not innate - although there may be a disposition for social development. It is something which develops over a number of years of steadily increasing interaction with the world. This process gradually enables the child to categorise things in the world into, perhaps initially, animate and inanimate (Warrington and Shallice 1984; and Humphreys, Riddoch, and Quinlan 1989); at a later stage to the formation of a mental/physical distinction; and finally to the processing of others behaviour, judgements about their mental states, and the formation of ap- 
propriate reactions to them. With experience this develops into the understanding, prediction and manipulation of the behaviour of others, requiring a high degree of social intelligence, or what Byrne and Whiten (1988) describe as the Machiavellian Intelligence Hypothesis (MIH).

The MIH is linked to primate social groups because it was originally thought that they were the only species which could formulate and put into use sophisticated forms of social knowledge. It is, after all, generally agreed that animals with intricate or complex social relations are likely to have fairly highly evolved forms of consciousness (Ristau 1991, p.297; see also Chance \& Mead (1953), Humphrey (1976) and Jolly (1966)).

With an MIH we may have our self-interest at heart, but we soon realise that to enhance our chances of survival we need to consider others, develop strategies, and even involve ourselves in an occasional bit of give and take. Having an understanding of the social structure of society means we can manipulate others whilst establishing and maintaining our bond with them.

This careful juggling of our social environment has been compared by Humphrey (1984), and Leakey \& Lewin (1992) to a game of social chess in which we need to be able to understand the worlds of other individuals; to recognise the alliances that have been built up between others; to discern how those others might benefit us; how to co-operate with them for a possible mutual reward; and if need be, how to manipulate them into behaving in a way that will further the pursuit of our own goals without alienating them.

We need to be able to pinpoint our goal, think ahead about what will be useful for its attainment, and plan the best strategy for achieving it. A difficult task at the best of times, but one that is further complicated by the sometimes unpredictable actions of others. To be successful social beings we have to learn to draw on previous experiences and relate these to our present, and our and other's possible future actions. 
This may seem trivial, we are social experts who interact on a daily basis with seemingly little effort, and who successfully achieve many of our goals, but years of practice have gone into our being this capable. Early on in our development we realise that there are others in our environment who are not us, and who don't necessarily have our thoughts and feelings. From a very young age we begin to realise that not all of our desires will be gratified immediately and we develop the skills of negotiation and planning for the future; both of which prove more successful the better we understand our social environment.

Its not yet clear that all animals have to be good at forward planning. Many non-social animals may survive by responding to changes in their environment as and when they happen. Certainly they will not need to occupy themselves with considerations of how a group is set up, what alliances there are between individuals, which are secure and which are vulnerable, or which individuals would be likely to help them overthrow the present group leader. Their concerns will be finding food, seeking security and acquiring a mate, when each becomes a priority.

Although social interaction is easy once you can do it not all humans share a disposition for social development. Successful interaction requires a good level of social understanding and this tends to be very poor in autistic individuals who have little or no grasp of their social environment. This lack of understanding is frequently accompanied by poor communication skills, and with poor communication and a deficient social ability their performance in the social environment will be greatly impaired.

If a social understanding is necessary on a larger scale, then the monitoring of events on a local or individual scale enabling one to predict what an individual is thinking or is likely to do next, is the very basis for it. Dealing effectively with how anothers behaviour affects you is only possible if you have a theory of mind. So what is meant by a theory of mind and why is it crucial for successful social interaction? 


\section{Theory of Mind}

Quite simply having a theory of mind allows us to imagine what others are thinking or feeling. For example, we can infer from our interaction with other human beings, and possibly even some other animals, that they have minds, which like our own, are occupied with beliefs, desires and so on.

An essential part of the underpinning of a theory of mind is the individuals detection of others as agents with their own goals and desires. Initially this comes under the animate / inanimate distinction, where animate things are assumed from their movement to have intentions, and where many of the ascriptions of mental states are misplaced, for example, a child may ascribe to building blocks a desire to fall down. Baron-Cohen explains this as an intentionality detector or $I D$, a perceptual device that interprets motion stimuli ... in order to be able to make sense of the universal movements of all animals (Baron-Cohen 1995, p.32-33).

The ID is object-centred because the perceiver interprets the objects actions in relation to the goals and desires they imagine the object to possess. The later theory of mind stage can be explained as being agent-centred because its how the agent interprets their world in relation to their attitude, or their perception of someone elses attitude, to that world. Each of these attitudes can, but need not necessarily, be expressed in the form of a propositional attitude statement that asserts a relationship to the world. For example, Norman hopes that it will be warm, or Ian knows that Jane wishes he were happy, and so on.

There are two very important aspects of a theory of mind, one, the relationships or attitudes can be many clauses deep - described as orders of intentionality; and two, they allow someones attitude statement to be true even if the embedded proposition to which it refers is actually false.

Being able to deal with levels of intentionality makes it possible for us to identify and keep track of complex relationships that exist between individuals. These can be expressed in ever more 
complex strings of attitude statements, for example, I realised that you knew that I knew about X or He thought that she believed that he wanted her to feel like going to the cinema - which have three and four orders of intentionality respectively. But, there is a limit to how many orders of intentionality we can follow with ease, and this limits the complexity of the social relationships that we can keep track of.

Being able to follow orders of intentionality is crucial, for we can understand that someone could hold a belief without their realising that the content of that belief, the embedded proposition, is in fact false. This ability offers us a tremendous social advantage.

The beliefs we have we hold to be true, if we did not hold them to be true we would revise them and hold different ones. If what others believe is different from what we believe we will consider their beliefs to be false. With a theory of mind we can detect someone holding a belief we believe to be false even though they believe it to be true. Thus, a common way of testing for the presence of a theory of mind is a false belief test. (See Dennett 1978)

Wimmer and Perner (1983) devised a test to show just this - the Sally-Anne Test. Sally and Anne are two dolls in a room with an experimenter and a child. Sally places a marble in her basket and then leaves the room. While she's out of the room Anne takes the marble from Sally's basket and puts it in her own basket. The child, observing all this action, is then asked where Sally will look for the marble when she re-enters the room. Children who have a theory of mind will say that Sally will look in her own box because that's where she last saw it. These children realise that Sally can have a false belief and that her belief is true as far as she's concerned. A child with no theory of mind will say that Sally will look in Anne's box for the marble because they will not imagine that Sally's belief about the marble would be any different from their own, and they saw the marble being put into Anne's box. 
So being able to believe both that "X believes $P$ " and that $\mathrm{X}$ is wrong in that belief is the core of social interaction for without this ability we couldn't follow and understand the thinking behind other people's actions. The best example of this is seen in Children's Fairy stories where someone is always being duped by someone else, for example, the wolf deceives Little Red Riding Hood, Hansel and Gretel deceive the wicked witch, and the wicked stepmother deceives Snow White. Children hear these stories at an age when they are learning to recognise pretend play in others and are able to respond by joining in the pretence. (See also Leslie (1987)) The development of a theory of mind is thus 'heralded by the onset of pretend play' (Baron-Cohen 1995, p.56).

If we cannot realise that others can have mental states, that those states can be different from our own, and that they manifest a false belief, we would be completely incapable of recognising deception or ourselves deceiving others.

If a theory of mind is crucial for understanding the mental lives that surround us in a social environment then you would expect to find a theory of mind present in the minds of at least some non-human social animals. Certainly it would seem to be something that is necessarily present in social primates since our primate minds are sensitive organs of empathy (Jolly, p.233), and being able to empathise with another is the first step to being able to follow their thinking and anticipate their future actions. If an animal is trying to reach imagined goals, it would be useful for it to also picture its social companions as having goals (Jolly 1991, p.232). Admittedly an animal's theory of mind might not include the large number of mental states that are associated with human society, but a recognition of a false belief in others might at least be present. This can be seen in cases of deliberate deception, where "'animal1 wants (animal2 to believe $\mathrm{X}$ )', where $\mathrm{X}$ is false" (Byrne \& Whiten 1991, p.128).

Obviously it is difficult to test the deliberate element of any action, however, some theorists say that some kinds of animal behaviour do satisfy this requirement, see for example, Waddington $(1972,1973)$ and Daanje (1951). The best way we have of testing for the presence of a theory of 
mind is by observing an animal's behaviour and looking for what we would consider appropriate signs. These might include the animal who is doing the deceiving keeping a wary eye on the animal they are intending to deceive just in case they look their way at an inopportune moment. Or, we might use Jollys criterion, that if we could assume that these observed behaviors indicated conscious purpose if shown by a human being then there is little reason to conclude that they fail to show conscious purpose in the animal exhibiting the behaviour (Jolly 1991, p.231).

\section{Deceptive behaviour in social animals}

Goodall provides many examples of animals using deception to gain advantage in her observations of primates in their natural habitat. One particular example is of an adolescent male chimp called Figan who deliberately suppressed his food barks when he didn't want others to know he had food because they would take it from him. You might argue that this is simply a case of selfcontrol, but even then its self-control for a purpose, and that purpose is not to raise the interest of the others because theyll come back and take the food. Figan's purpose seems to be to keep the others holding on to their false beliefs.

A more complex example of Figans deceptive behaviour, one where he can be seen to actively communicate false cues to others while keeping his own original goal firmly in mind, can be seen in this striding off into the woods as though heading for a place he knew food would be available, but on losing the adult males who had followed him, doubling back to get bananas he knew would be waiting for him - his original goal. Being able to distract the others in this way would seem to show a competent grasp of what the other chimps had in mind, pretending to lead them towards what they want, and, having misled them, returning to the pursuit of his original goal.

Group living can flourish when there is co-operation and a good system of communication, however, if cheating in the communication is perceived as providing a reward then the giving of misinformation will also flourish. With this in mind Cheney and Seyfarth offer a slightly different 
criterion for deception; conscious deceptive behaviour is that which provides others with false information. Figan's behaviour certainly complies with this criterion.

Some non-primates also exhibit deceptive behaviour. Rüppell (1969), describes a mother and cubs in an Arctic fox family group. The mother Arctic fox was competing for food with her several well-grown young; the latter resorted to such drastic competitive tactics as urinating in their mothers face in order to reach food morsels first. After several such encounters, the mother ... gave warning calls, otherwise used to signal dangers of various kinds and, when the youngsters

ran off, seized the food herself (Griffin 1981, p.96). Griffins comment on the mothers possessing at least short-term intentions and plans seems reasonable, for she seemed to know that she could distract her cubs by giving them false information, and then returning to her original goal.

Its clear from these examples, that many social animals behave in a way that may be considered consciously deceptive. If we follow Jollys criterion, and ascribe an intention to an action if it would be considered consciously intended when displayed by a human being, then many of the behaviours described above are consciously intended actions. They involve one social animal being able to deceive another by anticipating their goals and desires, and deceiving them into believing that these are being satisfied whilst pursuing their own distinct goals and desires.

Animals incapable of deception, to paraphrase Baron-Cohen, have a world that may be largely dominated by current perceptions and sensations. A world which would appear to be unpredictable (Baron-Cohen 1995, p.82). A world which may be largely similar to that of the autistic individual who has no theory of mind with which to deal effectively with the social world they inherit.

\section{Social implications for mindblind autistic children}

Mindblindness is a state where someone is not only unable to read the mind of another, but is also, literally blind to the fact that others have minds. We, as normal human beings, mindread all 
the time, effortlessly, automatically, and mostly unconsciously, (Baron-Cohen 1995, p.3) but autists generally do not. Someone suffering from mindblindness will often behave with others as though they are objects. They make the distinction between animate and inanimate categories of things, but not between mental and physical categories, and as a result they have great difficulty dealing effectively with their social environment.

One of the notable absences in the development of autistic children is learning how to pretend. In order to pretend, one must understand how pretending is different from not pretending ... in children with autism spontaneous pretend play is severely impoverished or altogether absent (BaronCohen 1995, p.76-77). Without this ability to pretend the autist is unable to distinguish real from unreal, or true from false.

This kind of existence can lead to problems especially with solving immediate problems and planning ahead. Because it is rare for autistic children to imagine a set of circumstances which is different from the one theyre dealing with now they cannot deal with what might be. They cant pretend, and they cant imagine that others have thoughts or that those thoughts are different from their own.

Without this capability and without a linguistic capability the autistic person can only deal with their social environment in a stilted and fumbled way. They will see no reason to co-operate, for co-operation is only worthwhile if theres an advantage to be had and no advantage can be provided by a non-mental, animate object. Similarly they will know no reason to deceive for their world cannot be other than it is.

It is very likely that if many autists are blind to their own past thoughts and to other peoples possibly different thoughts, their world must be largely dominated by current perceptions and sensations (Baron-Cohen 1995, p.82). Their lives may be just as full of trepidation as those of nonsocial animals since making sense of their surroundings is immensely difficult. But what makes 
the case of the autist so much worse is that they inherit a social group with which they cannot participate. The non-social animal has no social group to bewilder it.

Successful high-level social interaction seems impossible without a theory of mind, and one thing we might conclude from this is that sophisticated communication can only fully develop when a theory of mind has begun to emerge. Many autists can produce little language and it is often limited, unpredictable and poorly directed, and this results in awkward and unsuccessful communication. Perhaps we will discover that the ability of other species to communicate is related to their potential to develop a theory of mind. Until we have a better understanding of their varied forms of communication, and the relation of the neocortex to group size, we will not be able to say for sure. Whatever the case may be, a theory of mind is necessary if we are going to co-operate, manipulate and deceive our way successfully through life.

\section{Bibliography}

Baron-Cohen, S. (1993) Autism the Facts, Oxford University Press

Baron-Cohen, S. (1995) Mindblindness An Essay on Autism and Theory of Mind, MIT Press

Bennett, J. (1991) How is Cognitive Ethology Possible?, in Ristau, C. (Ed) (1991) Cognitive Ethology The Minds of Other Animals, Lawrence Erlbaum Associates

Boesch, C., \& Boesch, H. (1984) Mental map in wild chimpanzees: An analysis of hammer transports for nut-cracking, Primates, 25, 160-170

Byrne, R. \& Whiten, A. (1988) Machiavellian Intelligence: Social Expertise and the Evolution of Intellect in Monkeys, Apes, and Humans, Oxford University Press

Chance, M. R. A., \& Mead, A. P. (1953) Social behavior and primate evolution, Symposium of the Society of Experimental Biology VII, (Evolution), 395-439

Cheney, D. L. \& Seyfarth, R. M. (1990) How Monkeys See The World, Chicago University Press, Chicago 
Cheney, D. L. \& Seyfarth, R. M. (1991) Truth and Deception in Animal Communication, in Ristau, C. (Ed) (1991) Cognitive Ethology The Minds of Other Animals, Lawrence Erlbaum Associates

Daanje, A. (1951) One the locomotory movements in birds and the intention movements derived from them, Behaviour 3:48-98

Dawkins, M. S. (1995) Unravelling Animal Behaviour, Second Edition, Longman Group Limited

Dennett, D. (1978) Beliefs about beliefs, Behavior and Brain Sciences 4: 568-570

Dennett, D. (1987) The Intentional Stance, Cambridge, MA: MIT Press

Dunbar, R. (1996) Grooming, Gossip and the Evolution of Language, Faber and Faber, London

Goodall, J. (1986) The chimpanzees of Gombe, Cambridge, MA: Harvard University Press

Griffin, D. (1981) The Question of Animal Awareness, William Kaufman Inc.

Hayes, C. (1951) The ape in our house, New York: Harper

Humphrey, N. (1984) Consciousness Regained, Oxford University Press

Humphreys, G. W., Riddoch, M. J., Quinlan, P. T. (1988) Cascade processes in picture identification, Cognitive Neuropsychology, 1900, 5(1), pp. 67-103

Jolly, A. (1966) Lemur social behavior and primate intelligence, Science, 53, 501-506

Jolly, A. (1991) Conscious Chimpanzees? A Review of Recent Literature, in Ristau, C. (Ed) (1991) Cognitive Ethology The Minds of Other Animals, Lawrence Erlbaum Associates

Kenny, A. J. P., Longuet-Higgins, H. C., Lucas, J. R. \& Waddington, C. H. (1972) The Nature of Mind, Edinburgh University Press

Kenny, A. J. P., Longuet-Higgins, H. C., Lucas, J. R. \& Waddington, C. H., (1973) The Development of Mind, Edinburgh University Press 
Leakey, R. \& Lewin, R. (1992) Origins Reconsidered, Little, Brown

Leslie, A. (1987) Pretence and Representation: The origins of theory of mind, Psychological Review 94: 412-426

Lewin, R. (1992) Human Evolution, Blackwell

Menzel, E. W. (1971) Communication about the environment in a group of young chimpanzees, Folia Primatologia 15, 220-232

Menzel, E. W. (1974) A group of young chimpanzees in a one acre field, in Schreier, A. M. \& Stollnitz, F. (Eds), Behavior of nonhuman primates, 5, 83-153, New York: Academic Press

Premack, D. \& Woodruff, G. (1978) Does the chimpanzee have a theory of mind? Behavior and Brain Sciences 4: 515-526

Ristau, C. (Ed) (1991) Cognitive Ethology The Minds of Other Animals, Lawrence Erlbaum Associates

Rüppell, G. (1969) Eine Lüge als gerichtete Mitteilung beim Eisfuchs (Alopex lagopus L.), Z. Tierpsychol, 26:371-374

Shannon, C. \& Weaver, W. (1949) The Mathematical Theory of Communication, Urbana : University of Illinois Press

Warrington, E. \& Shallice, T. (1984) Category specific semantic impairments, Brain 107: 829854

Whiten, A. (1991) Natural Theories of Mind, Blackwell

Wimmer, H. \& Perner, J. (1983) 'Beliefs about beliefs: Representation and constraining function of wrong belief in young children's understanding of deception', Cognition 13: 103-128 